up without too much handling. This package is put into a small square pasteboard box. The original paper package is sterilized by heat and then the final package is sterilized in formalin in the same manner as all packages of the kind are sterilized.

When one wishes to use the gauze, the onion-skin paper can be lifted off from it and one or a number of pieces can be taken out with a sterile forceps. The pieces underneath are not touched and therefore can be left for later use. I am now having packages made containing twenty, fifty, and one hundred pieces.

11 West Ninety-first Street.

\section{A CASE OF TRAUMATIC FRON'TAL SINUSITIS}

OPERATION; A CURE DUE IN PART TO THF INJECTION OF BISMUTH PASTE; PRACTICALIYY NO DEFORMITY

\section{F. PHINIZY CALHOUN, AB., M.D. \\ ATLANTA, GA.}

There are always two important facts to be considered in any radical operation on the frontal sinus: first, deformity frequently follows the operation; and, second, the operation does not always effect a cure.

The case I report is one in which both of the bad results just mentioned have been avoided, and I attribute the cure to two injections of bismuth paste into the cavity.

History.-The patient, a healthy, robust-looking man, aged 41, consulted me May 23, 1908, on account of a continuous headache. He had consulted several oculists in neighboring eities for the same trouble, and glasses had been prescribed in each case. His headaches, restlessness at night and loss of appetite increased to such an extent during the few weeks prior to his visit to Atlanta that he had been referred by one doctor to another, with the hope of finding relief, and the patient stated that his trouble had been frequently diagnosed as incipient insanity and brain abscess. The patient attributed his present trouble to a blow which he received on March 27 , 1907 , while walking through the railroad yard of a neighboring city on a tour of inspection, when a heavy door of a refrigerator car suddenly swung open and the edge struck him on his right temple. He was knocked unconscious for a few hours and was confined to his bed for several weeks. After that time the headache increased in severity. March 19, 1908, two months before consulting me, a supposed polypus was removed from his right nose. There had never been a discharge from his nose.

Examination.-This showed a decided roughening of the right frontal eminence, over which there was a small sear in the skin, evidently from an old lacerated wound. On palpation there was tenderness, especially when pressing upward beneath the supraorbital ridge. There was a marked deviation of the nasal septum, high up, pressing against the middle turbinal body, the anterior end of which had been removed. This operation undoubtedly is what the patient thought to be the removal of a polypus. It was impossible to probe the nasofrontal duct. On transillumination there was a distinct shadow over the right side which might have been due to this bony thickening. An anterior skiagraph revealed a distinct difference in the two sides. This difference also might have been due to this bony thickening. A lateral view showed a very large sinus, and compared to a picture of the left side, the difference was marked. The patient's temperature, taken twice, morning and afternoon of the first day's examination, was a degree above normal.

Operation.-I was not sure, from my examination, that the patient had a purulent sinusitis, although $I$ was so convinced that there was something wrong that I advised an operation, exploratory, if necessary, and the patient readily consented. He was placed in the Wesley Memorial Hospital, May 26, 1908, and operated on the same day. My incision was along the upper margin of the right brow, extending down into the lat- eral side of the nose. The skin and periosteum were retracted and a small groove was made above the supraorbital ridge, when there flowed out a quantity of thick, yellow odorless pus, apparently under pressure. Most of the entire external wall of the frontal sinus was removed and the cavity was thoroughly curetted. The ethmoid cells were explored and found healthy. The nasofrontal duct was enlarged and gauze passed through it into the nose. The wound was packed lightly with iodoform gauze, and except for a slight drain at the inner angle of the skin wound, it was closed entirely.

Postoperative History.- On the fourth day the gauze in the cavity was removed through the nose, under gas anesthesia, and I considered it best and safest to pack the wound open through the brow incision. The wound was dressed daily for a while, then every other day until healing took place, nearly fourteen weeks after the operation. Two months later he returned with some puffiness over the scar, and with a probe a long sinus leading high up was discovered, out of which oozed a quantity of mucopurulent discharge. My colleague, Dr. C. R. Andrews, suggested the injection of bismuth paste into the cavity, as he had used it rather extensively in his orthopedic practice. It required but two injections, at intervals of four days, of the following formula to bring about a permanent cure:

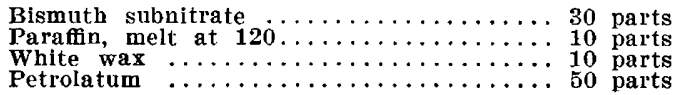

White wax $\ldots \ldots \ldots \ldots \ldots \ldots \ldots \ldots \ldots \ldots \ldots \ldots \ldots \ldots \ldots \ldots$ parts

More than a year has now elapsed with no evidence of a dis. charge, and the patient has been absolutely free from headache since the day following the operation. The cavity filled almost completely and the deformity is practically not noticeable. The cause of the infection was undoubtedly the compound fracture of the external wall of the right frontal sinus. An intracranial infection would have taken place eventually, as the external table was unusually thickened.

833 Candler Building.

\section{APPLICATION OF A SPLIN'T FOR FRACTURED - ULNA}

PENN-GASKELL SKILLERN, JR., M.D. PHILADELPHIA

I recently encountered a case of fracture of the ulna in which a new application of an old method seerned indicated. The solution of continuity occurred in the lower third of the shaft of the left ulna. The deformity, caused as usual by direct violence, was that the inferior fragment was driven outward, thereby encroaching on the interosseous space. Reduction by manipulation was evidently to be maintained by overabduction of the hand. Just so is overadduction aimed at in Colles' fracture.

How could the hand be secured in this position? The simplest method seemed to be to apply a Bond splint in reverse. The patient was furnished with a right-handed splint and instructed to grasp the semicylindrical block with his hand. The shaft of the splint, being free, formed an acute angle with the radial border of the pronated forearm. The hand was secured to the block by adhesive strips applied so as to describe an ellipse between the posterior surface of the bases of the metacarpals and the under surface of the distal end of the splint. The next manipulation accomplished with surprising satisfaction the result desired. The acute angle between the shaft of the splint and the forearm was obliterated by pushing the splint toward the forearm until it paralleled the latter. This of necessity forced the hand, bound to the block, over toward the radial side, in overabduction. The result was that the lower fragment of the ulna was drawn away from the radius as far as the interosseous ligament would permit, and thus the perfect coaptation of the fragments was obtained. 
A very pertinent reference to this fracture is the following:

Great care is necessary in the treatment of this fracture, lest the upper end of the lower fragment retains the vicious position into which it is forced at the time of the accident, and so is ultimately soldered to the inner margin of the radius. To prevent this occurrence the hand should be permanently inclined toward the thumb by two splints, the extremities of which are rendered somewhat sloping from behind forward, in a direction opposite to that of the splints sometimes employed in the management of fracture. of the corresponding end of the radius.

The principle, therefore, is an old one, but I think that it merits reconsideration, and that the single splint applied as described exactly meets the indications. It should be added that the leather side-pieces with which these splints are usually equipped were absent, since I was not convinced that they serve any practical purpose. Anyone may satisfy himself of the efficiency of this method by manipulating a splint in the manner indicated.

241 South Thirteenth Street.

\section{ARTIFICIAL INCREASE OF EOSINOPHILE CELLS IN DEMENTIA PRACOX}

\author{
R. E. WELLS, M.D. \\ Assistant Physician, Northern Michigan Asylum \\ TRAVERSE CITX, MICH.
}

Several months ago in an $\operatorname{article~}^{2}$ by Dr. H. D. Purdum and myself, we mentioned the increase in eosinophile cells in the blood, which is often seen in dementia præcox, and also mentioned two cases in which we succeeded in raising the percentage of eosinophiles by administration of thyreoidectin.

Since that time I have been testing the effect of thyreoidectin on the blood of cases of dementia pracox. The original idea for administering the drug was based on the theory that the disease was possibly caused by perverted secretion of the thyroid gland. Recently several cases of catatonia have been reported as having been cured or improved by partial extirpation of the thyroid gland. It was for this reason that it was thought that thyreoidectin might exercise the same influence on dementia præcox. No improvement in any of the cases was nuted, but it was observed that certain changes in the blood took place in most of the cases, which were characteristic.

The blood of ten cases of dementia præcox was examined at intervals of a few days during the administration of the drug. Five cases of catatonia and five cases of hebephrenia were taken at random. One case of epileptic insanity, one case of manic depressive insanity, one case of general paresis and a normal individual were also tested.

'The following tables show the blood changes in the cases of dementia præcox:

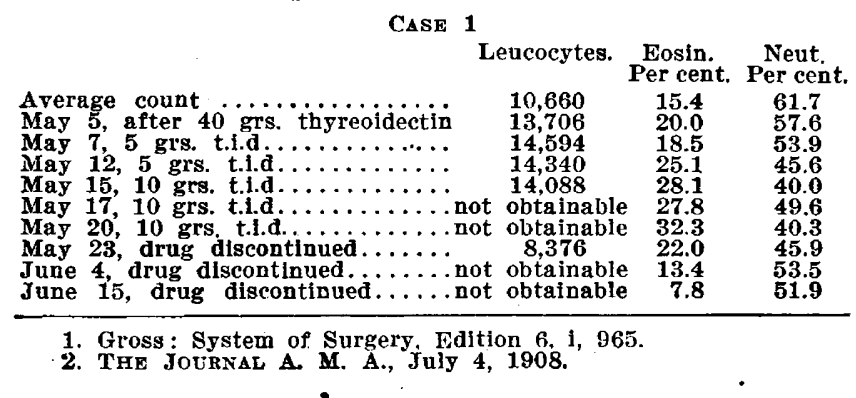

CASE 2

\begin{tabular}{|c|c|c|c|}
\hline & Leucocytes. & $\begin{array}{l}\text { Eosin. } \\
\text { Per cent. }\end{array}$ & $\begin{array}{l}\text { Neut. } \\
\text { Per cen }\end{array}$ \\
\hline Average count $\ldots \ldots \ldots \ldots \ldots \ldots$ & 6,592 & 6.0 & 61.4 \\
\hline May 7 , after 35 grs. thyreoldectin & 13,452 & 10.8 & 53.1 \\
\hline May 9,15 gis. t.i.d......... & 11,042 & 6.3 & 50.8 \\
\hline May 13,15 grs. t.i.d. . $\ldots \ldots \ldots$ & 8,884 & 14.2 & 49.6 \\
\hline May 26 , drug discontinued....... & $\mathbf{5 , 6 9 2}$ & 15.4 & 40. \\
\hline May 30 , drug discontinued. . . . . . & 8,756 & 9.6 & 62. \\
\hline June 1, drug discontinued.. & 7.482 & 8.3 & 37. \\
\hline June 5 , drug discontinued... & 6,996 & 12.4 & 48 \\
\hline June 15 , drug discontinued.. & 8,122 & 6.1 & \\
\hline June 22 , drug discontinued. . & 9.010 & 5.7 & $\mathbf{5 3 . 4}$ \\
\hline
\end{tabular}

\section{CASE 3}

Leucocytes. Eosin. Neut.

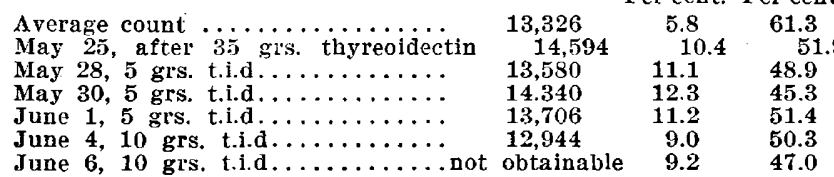

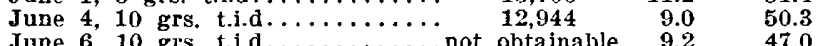

Case 4

Leucocytes. Eosin. Neut.

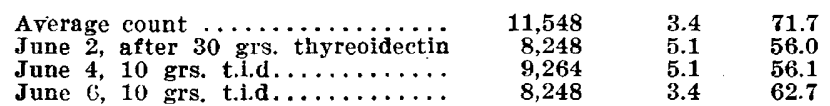

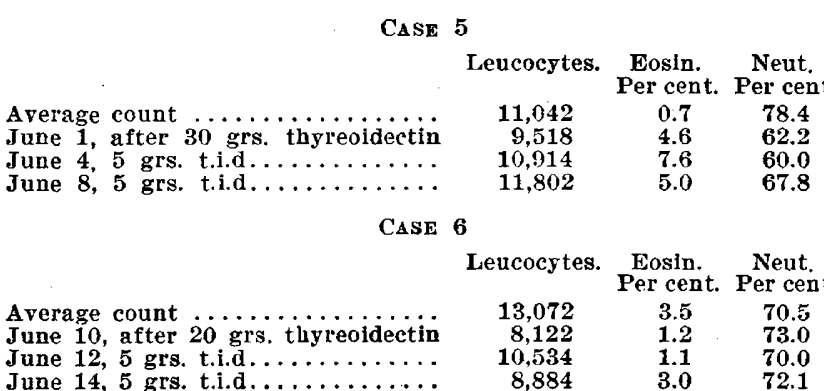

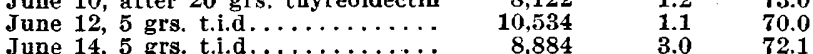

Case 7

Leucocytes. Fosin. $\begin{gathered}\text { Neut. } \\ \text { Per cent. Per cent. }\end{gathered}$

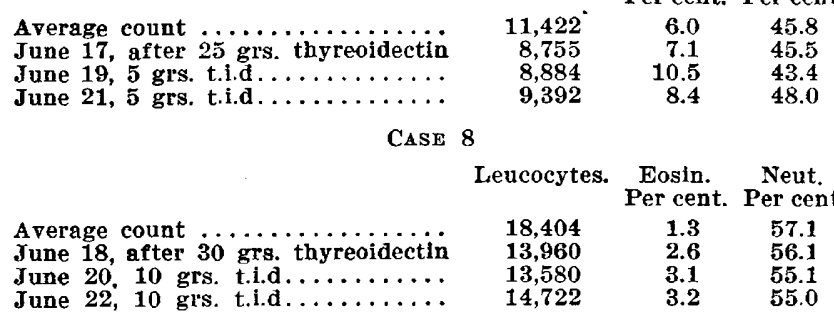

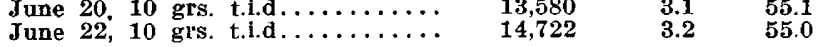

CASE 9

Average count $\ldots \ldots \ldots \ldots \ldots \ldots \ldots$.

Oct. 12, after is grs. thyreoidectin

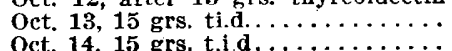

Leucocytes. Eosin. Neut.

$\begin{array}{rcc} & \text { Per cent. } & \text { Per cent. } \\ 9,392 & 1.2 & 67.8 \\ 10,660 & 1.7 & 70.2 \\ 9.898 & 1.4 & 76.0 \\ 10,888 & 2.4 & 63.6\end{array}$

Case 10

Leucncytes. Eosin. Neut.

Average count $\ldots \ldots \ldots \ldots \ldots \ldots \ldots . \quad 8,168 \quad \begin{array}{cc}\text { Per cent. Per cent } \\ \text {. }\end{array}$

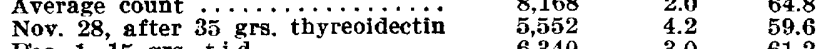

Dec. 1, 15 grs. t.i.d..........

- In making the differential counts in these cases, at least 500 white blood cells were counted and often a thousand. They were all counted by one person. Wright's blood stain was used.

The most notable variations in the blood are the increase in the eosinophile cells in 90 per cent. of the cases and the decrease in the neutrophiles, the latter, as a rule, showing a greater decrease in proportion than the rise in eosinophiles. Case 6 is the only one in the series in which there was no rise in the eosinophiles. It 